\title{
O turismo no espaço rural como atividade complementar de geração de renda e ocupação não agrícola no Corede das Hortênsias do Estado do Rio Grande do Sul, Brasil
}

El turismo en el espacio rural como actividad complementaria de generación de ingresos y empleo rural no agrícola en el Corede das Hortênsias do Estado do Rio Grande do Sul, Brasil

Rural tourism as a complementary activity of income generation and nonagricultural rural employment in Corede das Hortênsias of the State of Rio Grande do Sul, Brazil

http://dx.doi.org/10.18472/cvt.17n1.2017.1150

Rafael Lima de Souza 〈rafael@giraomundo.br >

Universidade de Caxias do Sul (UCS), Caxias do Sul, RS, Brasil.

Eurico de Oliveira Santos 〈eurico58@terra.com.br >

Universidade de Caxias do Sul (UCS), Caxias do Sul, RS, Brasil.

Humberto Thomé-Ortiz 〈humbertothome@hotmail.com >

Universidad Autónoma del Estado de México (UAEM), Toluca, México.

CRONOLOGIA DO PROCESSO EDITORIAL

Recebimento do artigo: 25-out-2015

Aceite: 12-dez-2016

FORMATO PARA CITAÇÃO DESTE ARTIGO

SOUZA, R. L. de; SANTOS, E. O.; THOMÉ-ORTIZ, H. O turismo no espaço rural como atividade complementar de geração de renda e ocupação não agrícola no Corede das Hortênsias do Estado do Rio Grande do Sul, Brasil. Caderno Virtual de Turismo. Rio de Janeiro, v. 17, n. 1, p. 171-186, abr. 2017.

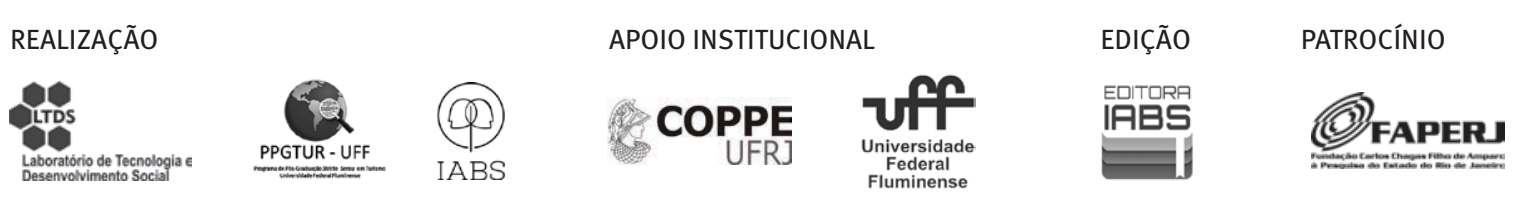




\section{RESUMO}

Entre os resultados das transformações que aconteceram no meio rural, com a entrada das atividades não agrícolas como fonte de renda para as famílias rurais, o turismo é uma delas. Nesse turismo, o habitante urbano interage com o meio ambiente rural, com uma suposta possibilidade de que as famílias rurais aumentem seus rendimentos e também diversifiquem suas atividades. Existem poucos estudos que analisam, quantitativa e qualitativamente as características dos empregos e a renda gerada pelas atividades turísticas. O objetivo desta pesquisa foi descobrir se o turismo no espaço rural pode ser considerado uma atividade para geração de renda no meio agropastoril no Corede das Hortênsias, bem como determinar se existe um padrão de geração de emprego nos setores primário e terciário. Os resultados mostram que houve um aumento nos rendimentos das famílias e que a maioria das vagas de emprego é temporária devido à sazonalidade da atividade. Concluímos que o turismo é uma atividade complementar que contribui para a economia rural da zona estudada.

Palavras-chave: Turismo no espaço rural. Agroturismo. Empregos temporários rurais. Censo. Corede. Hortênsias. Rio Grande do Sul.

\section{ABSTRACT}

As a result of the transformations occurring in rural areas, it is necessary to include non-agricultural activities as a source of income for the peasant families, one of these activities is tourism. Rural tourism allows interaction between the urban population and rural areas and presupposes the possibility for rural families to increase their income and diversify their activities. Despite this, there are few studies that analyze, quantitatively and qualitatively, the characteristics of employment and income generated by tourism. The objective of the research was to determine if rural tourism can be considered an activity for the generation of non-agricultural income in COREDE das Hortênsias, as well as to determine the pattern of job creation in the primary and tertiary sectors. The results show that tourism increased family income and that most of the jobs generated are temporary due to the seasonal nature of the activity. It is concluded that tourism is a complementary activity that contributes to the rural economy in the study area.

Keywords: Tourism in rural areas. Agritourism. Nonfarm rural employment. Census. COREDE. Hortênsias. Rio Grande do Sul.

\section{RESUMEN}

Como resultado de las transformaciones ocurridas en el medio rural, es necesaria la inserción de actividades no agropecuarias como fuente de ingresos para las familias campesinas, siendo una de esas actividades el turismo. Este tipo de turismo, además de permitir la interacción entre el habitante urbano y el medio ambiente rural, supone la posibilidad de que las familias rurales aumenten sus ingresos y diversifiquen sus actividades. Pese a ello, existen pocos estudios que analicen, cuantitativa y cualitativamente, las característicos del empleo y los ingresos generados por la actividad turística. El objetivo de la investigación fue averiguar si el turismo en el espacio rural puede considerarse una actividad para la generación de ingresos no agropecuarios en el COREDE de las Hortênsias, así como determinar el patrón de generación de empleos de los sectores primario y terciario. Los resultados muestran que la actividad aumentó los ingresos de las familias y que la mayoría de los empleos generados son temporales debido a la naturaleza estacional de la actividad. Se concluye que el turismo es una actividad complementaria que contribuye a la economía rural en la zona de estudio.

Palavras clave: Turismo en el espacio rural. Agroturismo. Empleo temporal rural. Censo. COREDE. Hortênsias. Rio Grande do Sul. 


\section{Introdução}

A vida urbana, na contemporaneidade, vem acompanhada pelo constante desgaste físico e psicológico das pessoas, associado ao estilo de vida global das grandes cidades. Esses são os principais motivos do desejo de fugir do cotidiano e da cada vez mais frequente busca pela natureza, do reencontro com lugares que fizeram parte da história pessoal dos turistas. Em sintonia com essa dinâmica moderna e a falta de perspectiva na agricultura e na pecuária, processo que teve início na década de 1960, a partir da mecanização do campo, a utilização de insumos agrícolas industrializados e seleção de sementes, vislumbrando a exportação, tornou-se insustentável a condição de pequenos produtores, o que resultou no êxodo rural e na inversão da pirâmide populacional rural e urbana. Deve-se considerar também a atração das cidades pelo processo de industrialização.

A falta de políticas públicas e a importância, cada vez menor, da agricultura familiar na ocupação produtiva, fizeram com que uma grande parcela da população do campo entrasse em elevada estagnação econômica. Assim, a busca por atividades complementares à produção agropecuária se mostrou como uma das possibilidades desses produtores para garantirem a sobrevivência (FAO, 2014).

Novos arranjos econômicos passaram a configurar o cenário do campo quando o conceito de ruralidade passou a fazer parte do imaginário de preservação da natureza, dando-se na forma de práticas relacionadas às atividades não agrícolas como, por exemplo, a industrialização de produtos agropecuários, prestação de serviços, como pode ser o turismo.

Segundo Schneider (2003a, p. 22):

[...] o que está acontecendo, no entanto, é que o rural não mais se resume à atividade econômica agrícola, pois a ele passaram a incorporar-se, nas leituras analíticas e nas representações sociais, outras dimensões como a natureza, as famílias rurais, as paisagens, o patrimônio cultural e as tradições, entre outras.

Com base na inserção da atividade turística no campo, seja na forma de turismo rural, seja na forma de agroturismo, foi realizado este estudo em uma região específica do estado do Rio Grande do Sul, onde a prática do turismo no espaço rural começou a ser explorada, procurando identificar as particularidades da região e tentando evidenciar as diferentes percepções dos proprietários rurais em relação à atividade. Nosso objeto de estudo foi o Conselho Regional de Desenvolvimento (Corede) ${ }^{1}$ das Hortênsias. O Corede das Hortênsias, localizado na Região Funcional de Planejamento 3, foi criado em 1991, e é composto por sete municípios: Cambará do Sul, Canela, Gramado, Jaquirana, Nova Petrópolis, Picada Café e São Francisco de Paula. Encontra-se próximo à Região Metropolitana de Porto Alegre e ao Centro Regional de Caxias do Sul, que acabam por polarizar seus principais serviços.

O objetivo deste estudo foi verificar se o turismo no espaço rural pode ser considerado atividade complementar de geração de renda e ocupação não agrícola na região, bem como estabelecer o perfil da geração de emprego e renda nos setores primário e terciário no Corede.

Este artigo está dividido em quatro partes, na primeira apresenta-se a introdução, na segunda parte o aporte bibliográfico com o intuito de elucidar conceitos como a Pluriatividade, a Atividade não Agrícola e

1 Para contribuir para o crescimento e desenvolvimento regional foram criados os Conselhos Regionais de Desenvolvimento (Coredes). São associações civis, sem fins lucrativos, criadas pelo governo do estado por meio da Lei n. 10.283 do dia 17 de outubro de 1994. Os Coredes buscam uma coordenação geral entre os diferentes atores sociais, políticos e econômicos das regiões, fomentando uma organização. (Santos, et al., 2014). 
o Turismo no Espaço Rural. Na terceira parte fala-se a respeito da metodologia aplicada, na quarta parte foram apresentados os resultados da pesquisa e, para finalizar, as considerações finais.

\section{A pluriatividade}

A pluriatividade é um fenômeno que se caracteriza pela combinação de múltiplas atividades profissionais de pessoas pertencentes a uma mesma família. Normalmente, a pluriatividade acontece quando membros que compõem famílias rurais mesclam atividades agrícolas com outras formas de emprego em atividades não agrícolas. Fuller (1983), um dos pesquisadores que iniciaram a discussão desse tema, coloca que a ideia de pluriatividade possibilita analisar com clareza a maneira como o trabalho é organizado pelas famílias rurais, em diferentes tipos de atividades, também, possibilita a criação de distintos padrões, individuais e coletivos, de como se dá a distribuição do trabalho rural.

Esse fenômeno pressupõe a mistura de duas ou mais atividades, sendo uma delas sempre a agricultura. Essa interação entre atividades distintas tende a intensificar de acordo com a complexidade das relações entre os agricultores e o ambiente social e econômico em que estiverem inseridos. Schneider (2003a, p. 91) corrobora:

[...] um fenômeno através do qual membros das famílias de agricultores que habitam no meio rural optam pelo exercício de diferentes atividades, ou mais rigorosamente, optam pelo exercício de atividades não agrícolas, mantendo a moradia no campo e uma ligação, inclusive produtiva, com a agricultura e a vida no espaço rural [...]

Nas três últimas décadas, a agricultura do Rio Grande do Sul, bem como a dos demais estados do sul do Brasil, conheceu um desenvolvimento econômico sem precedentes em sua história. Esse desenvolvimento, o mesmo que ocorreu na maior parte dos países desenvolvidos, foi marcado pelo surgimento de novas tecnologias, pela utilização em larga escala de maquinário e insumos, pela introdução de variedades de plantas e animais de alto rendimento por meio de alterações biogenéticas. O resultado desse avanço, por um lado, foi um grande crescimento na produção agrícola, em especial, dos grãos como a soja e o milho, que geraram um ganho na quantidade colhida em relação à área plantada.

Por sua vez, com esse desenvolvimento tecnológico, o tempo gasto pelos produtores rurais nas atividades agrícolas diminuiu, trazendo a necessidade de buscar outras fontes de renda. As propriedades rurais estudadas apresentam poucos trabalhadores e existe a necessidade de diversificar as atividades produtivas por meio do turismo.

A partir daí, algumas formas de agricultura que antes eram muito condenadas, como a agricultura em tempo parcial, passaram a ser aceitas como condição imperativa para a reprodução do espaço rural. É nesse contexto que surge a pluriatividade como agente de mudanças da economia rural, dando um novo sentido ao processo de produção rural (MATTEI, 2005).

Segundo Anjos (2003), a inserção da tecnologia reflete diretamente na capacidade de absorção e retenção da população rural ativa e ocupada. O mesmo autor acrescenta que é possível que essa parcela da população que fica restrita às atividades agrárias não precise, necessariamente, sair do seu lugar de origem, assim, buscando no próprio espaço rural alternativas de atividades fora do bojo da agricultura. 
Esse processo pode ser evidenciado na Espanha por meio da seguinte citação:

Análogamente a lo ocurido en otros países modernos, inmersos en lo que podría ser conceptuado como la crisis del paradigma urbano-industrial, se experimentan hoy en el medio rural español tendencias hacia la desagrarización de la actividad productiva y económica, y a la tercerización de la misma; es decir, la agricultura pierde peso en el conjunto de las actividades que se desarrollan en dicho medio, en el que se está produciendo una paulatina diversificación económica, con la consiguiente extensión de la pluriactividad y la multifuncionalidad. (RUBIO, 2010, p. 271)².

É importante que essas famílias deixem de lado o costume de viver unicamente de atividades agrícolas e consigam abrir um leque de possibilidades, pois "admite-se não ser mais possível assegurar ingressos econômicos suficientes a todas as famílias baseados somente na agricultura” (ANJOS, 2003, p. 73).

Dessa forma, a partir de tais transformações que o espaço rural vem sofrendo, deu-se a utilização de termos como: "part-time farming", ou agricultura de tempo parcial e pluriatividade, entretanto reconhece-se o risco da divisão das atividades tradicionais do campo, tendendo a construir um processo de rururbanização.

\section{Atividades não agrícolas}

Diversos foram os fatores que colaboraram para a emergência das atividades não agrícolas; esse processo de transformação estrutural pode ser dividido em três fases distintas (SCHNEIDER, 2003b). A primeira delas, iniciada na década de 1970, quando os governos militares empreenderam uma inédita transformação de algumas regiões agrárias brasileiras, decorrente do que se chama de "urbanização do campo", um processo resultante de um transbordamento das cidades e de trabalho urbano para áreas rurais situadas em seu entorno. O processo de urbanização do campo se deu por meio da expansão de novas atividades que pouco ou nada tinham a ver com a produção agropecuária. Referem-se a novas ocupações ligadas ao lazer e ao ócio, atividades especialmente ligadas à prestação de serviços (THOMÉ, 2008, 2010) e sobre o papel das residências secundárias no imaginário e simbólico das populações urbanas (CORREA, 2016).

A segunda fase seria decorrente da crise do próprio setor agrícola, particularmente a partir das dificuldades enfrentadas pelo setor agroexportador instaladas no início da década de 1990. A queda dos preços não apenas afastou os interessados em obter lucro com o negócio agrícola como diminuiu, rapidamente, as rendas gerais na agricultura brasileira.

A terceira fase, o período mais recente, impôs uma nova realidade política e econômica ao meio rural, com uma drástica diminuição no intervencionismo do Estado e muitas mudanças sociais e produtivas originadas, em sua maioria, da liberalização comercial, os efeitos disso possuem magnitude sem precedentes. De acordo com Schneider e Fialho (2000, p. 5):

Os efeitos sociais resultantes dessas mudanças variaram de região para região e pode-se arrolar, entre outros, uma forte modificação demográfica no meio rural, com a diminuição constante do número de famílias dedicadas às atividades propriamente agrícolas, o que repercutiu sobre a estrutura de ocupação e força de trabalho rural.

\footnotetext{
2 "À semelhança do que aconteceu em outros países modernos, imersos no que pode ser conceituada como a crise do paradigma urbano-industrial, hoje, na zona rural espanhola, existe uma tendência para a desagrarização da produção e da atividade econômica, e para a terceirização da mesma; ou seja, a agricultura perde peso em todas as atividades que ocorrem nesse ambiente, que está atualmente passando por diversificação econômica gradual, estendendo assim a pluriatividade e multifuncionalidade".
} 
Existem, também, outras razões apontadas como responsáveis pela emergência das atividades não agrícolas no meio rural brasileiro. Uma delas está ligada ao processo de descentralização e interiorização de determinados tipos de indústrias, especialmente de bens de consumo não duráveis, como têxteis, vestuários e calçados (SCHNEIDER, 2003).

Nas grandes mudanças da agricultura é de grande valia destacar alguns estudos a respeito do crescimento das atividades não agrícolas no meio rural como uma tendência em determinadas áreas. Schneider (2003) destaca que de fato a agricultura já não é mais sinônimo de exclusividade rural e observa que, nas regiões chamadas essencialmente rurais, são os setores não agrícolas que oferecem, cada vez mais, as maiores possibilidades de empregos no meio rural. Entretanto, as transformações da nova ruralidade podem-se também entender como penetração dos modelos econômicos dominantes no espaço rural. Nossa posição reconhece o caráter ambíguo das novas atividades rurais, por uma parte existe risco de perder a identidade rural e, por outra, a necessidade de gerar processos de transformação socioeconômica para a sociedade rural.

\section{Turismo no espaço rural}

A gama de denominações destinadas às atividades turísticas que são desenvolvidas no espaço rural traz a necessidade de se utilizar a generalização "Turismo no Espaço Rural” (TER). Os autores Roque e Mendonça (1999, p. 145) defendem a utilização desse termo genérico para definir "toda maneira turística de visitar e conhecer o ambiente rural, enquanto se resgata e valoriza a cultura regional”.

Já Oxinalde considera sinônimos os termos Turismo Rural e Turismo no Espaço Rural (apud SILVA; VILARINHO; DALE, 2000, p. 16) quando define que "turismo rural engloba modalidades de turismo, que não se excluem e que se complementam, de forma tal que o turismo no espaço rural é a soma do ecoturismo e turismo verde, turismo cultural, turismo espontâneo, agroturismo e turismo de aventura”.

Crosby e Moreda (1996) se valem dos termos "turismo em áreas rurais" e "turismo rural" com equivalência e os definem como qualquer atividade relacionada ao turismo que se desenvolva no meio rural, ainda, considerando como parte deste todas as áreas naturais inclusive litorâneas. Para Zimmermman (2000, p. 130):

As atividades turísticas nos meios naturais tem recebido uma proliferação de termos, que fazem referências ao turismo rural: turismo de interior, turismo verde, turismo diferente, turismo alternativo, turismo rural e ecológico e por aí afora. Evidentemente, cada atividade possui características próprias, que, dependendo das características geomorfológicas do espaço podem estar juntas, sob a denominação genérica de turismo rural.

Ainda, no caderno Diretrizes para o Desenvolvimento do Turismo Rural:

Entende-se Turismo no Espaço Rural como um recorte geográfico, [...] as muitas práticas turísticas que ocorrem no espaço rural não são, necessariamente, Turismo Rural, e sim atividades de lazer, esportivas ou ócio de citadinos que ocorrem alheias ao meio que estão inseridas (BRASIL, 2003, p. 7).

Pode-se aduzir que, para além da proliferação de todos esses termos utilizados, o próprio termo "turismo rural" pode ser analisado sob uma nova ótica. De acordo com Froehlich e Rodrigues (2000), na atualidade, fica muito complicado que as dualidades rural/urbano, tradicional/moderno e cidade/campo sejam levadas como verdade, isso porque, segundo os autores, houve um "transbordamento" do que se considerava urbano para o rural, fazendo com que as características de ambos se sobrepusessem. Isso 
ocorre em diversos lugares do mundo como, por exemplo, na Espanha, como se pode observar na citação de Pérez-Díaz:

[...] se produjo un proceso de transformaciones en la sociedad rural española, cuyas formas de vida, hábitos y pautas culturales fueron poco a poco dejando de lado su tradicional carácter rural y autárquico-localista, a la vez que eran penetradas, cada vez con mayor intensidad, por lo urbano (PÉREZ-DÍAZ, 1983, p. 255)3.

Anos mais tarde, Toledo (1998) acrescenta alguns fatores que ajudaram a dissolver as fronteiras entre o rural e o urbano. O autor aponta que:

[...] las demarcaciones territoriales rural/urbano cada vez son menos nítidas y más difusas, de tal forma que, en las actuales sociedades modernas avanzadas, el cambio tecnológico, la transmisión de la información y de la cultura, los nuevos medios de transporte, y, en definitiva, el proceso general de globalización en el que estamos inmersos, tienden a disolver progresivamente las fronteras socioeconómicas entre tales demarcaciones (TOLEDO, 1998, p. 172) ${ }^{4}$.

Corroboram essa construção Del Grossi e Silva (2002) ao analisarem a crescente urbanização do meio rural, processo denominado "Novo Rural", onde "um conjunto de atividades não agrícolas, ligadas à moradia, ao lazer e a várias atividades industriais e de prestação de serviços são inseridas no espaço antes destinado exclusivamente à produção agrícola” (DEL GROSSI; SILVA, 2002, p. 5).

Rodrigues (2000) traz exemplos práticos que reforçam a ideia de falência da dualidade entre o urbano e o rural, ela cita bairros rurais que, ao serem decretados distritos, devido a um desmembramento municipal, são considerados urbanos, ainda que apresentem características tipicamente rurais. Para essa autora, até mesmo o termo "turismo" deve ser repensado em muitos casos que não envolvem pernoite como, por exemplo, chácaras alugadas para festas e empreendimentos de pesque e pague. Em nosso ponto de vista é um fenômeno amplo que pode representar risco e oportunidades para as comunidades rurais, por isso a importância de conhecer seu papel na geração de emprego e renda complementar nas atividades tradicionais do campo.

Nos últimos anos, houve vários artigos científicos que abordam a importância do turismo no espaço rural para a geração de renda (BLANCO, 2004; MANOSSO; SOLOMÉ; CARVALHO, 2010; PELLIN, 2004; SILVA; DE FRANCISCO; THOMAZ, 2010).

O presente estudo aborda a relação entre turismo e a geração de renda, delimitando o objeto do estudo ao Corede como espaço de análise, ao mesmo tempo que mostra as contribuições do setor primário e terciário para o desenvolvimento econômico do espaço rural. Um estudo similar já foi desenvolvido em outra região da Metade Sul do estado do Rio Grande do Sul, Brasil (SANTOS; VIANNA; GULLO, 2012).

3 “[...] houve um processo de transformações na sociedade espanhola rural cujos estilos de vida, hábitos e padrões culturais foram lentamente deixando de lado seu tradicional caráter rural, local e autárquico, enquanto o campo era penetrado, com maior intensidade, pelo urbano".

4 "Os limites territoriais rural/urbano são cada vez menos claros e mais difusos, de modo que nas sociedades modernas, a mudança tecnológica, a transmissão de informações e cultura, novos meios de transporte, e, em última instância, o processo geral de globalização em que estamos imersos, tendem a dissolver gradualmente fronteiras socioeconômicas entre essas demarcações”. 


\section{Metodologia}

Esta pesquisa teve como objeto de estudo a região do Conselho Regional de Desenvolvimento das Hortênsias, que faz parte dos Conselhos Regionais de Desenvolvimento do Estado do Rio Grande do Sul. Esses Conselhos caracterizam-se por ser um fórum de discussão e decisão a respeito de políticas e ações que visam ao desenvolvimento regional e foram criados oficialmente pela Lei 10.283, de 17 de outubro de 1994 (COREDE, 2010a; COREDE, 2010b).

O Corede das Hortênsias é composto por sete municípios (Cambará do Sul, Canela, Gramado, Jaquirana, Nova Petrópolis, Picada Café e São Francisco de Paula), abrange uma área territorial de 6.261,7 $\mathrm{km}^{2}$, possui população total de 128.865 habitantes e sua densidade demográfica é de $20,4 \mathrm{hab} . / \mathrm{km}^{2}$. O Produto Interno Bruto - PIB per capita (em 2010) foi de R $\$ 17.474$, de acordo com os dados da Fundação de Economia e Estatística do Rio Grande do Sul (FEE, 2011).

O tipo de pesquisa escolhido para o desenvolvimento deste trabalho foi quali-quantitativo de natureza exploratória. Segundo Malhotra (2006), a pesquisa pode ser classificada como exploratória ou conclusiva. A pesquisa exploratória tem como principal objetivo ajudar a compreender a situação-problema enfrentada pelo pesquisador (BOAVENTURA, 2004).

O problema de pesquisa do presente estudo está ligado à visão geral de uma situação que envolve a compreensão das limitações e possibilidades do turismo no espaço rural como atividade complementar de geração de renda e ocupação não agrícola nas propriedades rurais ativas, em relação à atividade turística, do Conselho Regional de Desenvolvimento (Corede) das Hortênsias, no estado do Rio Grande do Sul, Brasil. As respostas obtidas não são conclusivas, mas têm por objetivo compreender uma situação para, posteriormente, levantar hipóteses que poderão ser testadas.

A pesquisa exploratória é a mais adequada ao objetivo deste estudo porque provê critérios e compreensão, o processo de pesquisa é flexível e não estruturado, e a análise dos dados primários é qualitativa (SILVERMAN, 2009). A amostra obteve-se mediante o método não probabilístico da bola de neve (BERG, 2006), a partir do qual foram determinadas as propriedades rurais que encontram-se envolvidas nas atividades turísticas.

Nessa perspectiva, a pesquisa foi realizada em duas etapas, a primeira etapa foi de caráter exploratório para investigar as propriedades existentes e ativas no Corede das Hortênsias que se enquadrariam neste estudo. Para isso, foram utilizados dados disponibilizados pela Secretaria Estadual de Turismo, pela administração do Corede, pelas prefeituras dos municípios, bem como pelas Secretarias de Turismo dos municípios onde foram feitas as pesquisas e ainda informações dos proprietários rurais.

Os empregos gerados pelo desenvolvimento da atividade turística foram divididos em duas categorias:

A. Empregos diretamente relacionados com a direção e o funcionamento da indústria turística.

B. Empregos indiretos criados pelo turismo, que surgem derivados do montante de recursos obtidos pelas atividades produtivas dos residentes locais.

No segundo momento foram visitados todos os estabelecimentos (censo) citados a seguir e que se encontravam ativos no período de setembro a novembro de 2014 para a realização de uma entrevista semiestruturada com os proprietários. Detectou-se que os municípios de Gramado e Picada Café não possuem propriedades rurais ativas em relação à atividade turística cadastrada na Setur - RS. 
Tabela 1 - Lista das propriedades ativas do Corede das Hortênsias

\begin{tabular}{|c|c|}
\hline Propriedades & Localização \\
\hline Pampa Rural, Pesca e Lazer & Cambará do Sul \\
\hline Pousada das Corucacas & Cambará do Sul \\
\hline Eco parque Sperry & Canela \\
\hline Parque Fazenda da Serra & Canela \\
\hline Pousada Fazenda a Casa do & Jaquirana \\
\hline Mousada Bienenfreund & Nova Petrópolis \\
\hline Pousada Verde Vale & Nova Petrópolis \\
\hline Recanto dos Pioneiros & Nova Petrópolis \\
\hline Fazenda Hotel Invernadinha & São Francisco de Paula \\
\hline Fazenda Remanso do Faxinal & São Francisco de Paula \\
\hline
\end{tabular}

Fonte: Pesquisa de campo, 2014.

As entrevistas foram realizadas com perguntas abertas e fechadas, elaboradas especialmente para este estudo, e foram investigados os seguintes tópicos:

- Dados de identificação dos proprietários e da propriedade;

- Caracterização dos atrativos das propriedades;

- Informações sobre a atividade primária;

- Informações sobre a infraestrutura;

- Empregos fixos e temporários;

- Potencial turístico da propriedade;

- Motivação e permanência na atividade turística;

- Perfil e motivação dos turistas que frequentam a propriedade;

- Situação conjuntural com o setor primário;

- Comentários pessoais e conversas complementares.

As respostas às questões fechadas foram tabuladas e analisadas a partir das categorias de respostas apresentadas nas entrevistas, analisando-se de forma descritiva conforme a frequência de respostas apresentadas a cada categoria. As abertas foram analisadas mediante análise de conteúdo.

A análise qualitativa envolve duas atividades centrais: (1) desenvolvimento da consciência de que dados podem ser examinados e como eles podem ser descritos e explicados; (2) desenvolvimento de uma série de atividades práticas adequadas aos tipos de dados e grandes quantidades que deverão ser examinadas (GIBBS, 2009). 
A atividade 1 compreende vários estilos analíticos para a explicação do problema, como a descrição densa (GEERTZ, 2003), que demonstra riqueza do que está acontecendo e enfatiza a forma como isso envolve as interações. A atividade 2 compreende as etapas práticas que deverão ser cumpridas para que a análise de conteúdo seja possível.

Foram cumpridas as seguintes etapas práticas determinadas por Silverman (2009):

1. Documentação e transcrição das entrevistas com os proprietários rurais;

2. Pré-análise dos dados coletados;

3. Codificação e categorização dos dados por meio da seleção das informações relevantes e categorização dos dados de acordo com os construtos a serem estudados;

4. Interpretação dos dados por meio da análise dos dados extraídos da etapa anterior;

5. Elaboração do relatório de resultados por meio da explicitação de evidências e consolidação de resultados comparativos, que mostrem a relação entre diferentes modelos produtivos rurais, a atividade turística e o emprego.

\section{Resultados}

Não é todo empreendimento turístico que tem por objetivo direto a geração de emprego, mas, com certeza, esse é um dos resultados mais comuns, isso porque o turismo, por ser uma atividade que pertence ao setor de serviços, tem como característica gerar novas vagas de trabalho e diferentes tipos de ocupações.

No local estudado encontramos três modelos diferentes de propriedades rurais produtivas:

1) Um modelo tradicional em que se desenvolvem as atividades de agricultura e pecuária;

2) Um modelo turístico em que se desenvolvem as atividades exclusivamente do turismo;

3) Um modelo misto onde se desenvolvem as atividades de agricultura, pecuária e do turismo.

Nos três modelos existem diferenças de modalidades dos empregos; podemos classificá-los de empregos Fixos e Temporários. Entende-se por emprego fixo aquela modalidade em que o trabalhador tem Carteira de Trabalho assinada pelo dono da terra, entre os trabalhos que desenvolvem as pessoas que trabalham encontram-se: capataz, peão, caseiro, cozinheira, aguador e tratorista. Já os empregos temporários são aqueles que não têm nenhum vínculo de trabalho permanente, os trabalhadores são contratados em alguns meses do ano, entre as tarefas desenvolvidas por estes encontram-se esquiladores ${ }^{5}$, safristas ${ }^{6}$, domadores ${ }^{7}$, recreacionistas e alambradores ${ }^{8}$.

Segundo o que foi verificado no Corede das Hortênsias, grande parte dos empregos diretos gerados pela atividade turística exige mão de obra pouco qualificada, o que quase sempre também representa salários mais baixos. Lage e Milone (2000) esclarecem que, por essa razão, o turismo torna-se uma atividade com

\footnotetext{
5 Um esquilador é o profissional que trabalha na tosquia de carneiros, ou seja, quem corta os pelos dos carneiros para tirar a lã ou mesmo para prepará-los para exposições. 0 termo esquilador é comumente usado no estado do Rio Grande do Sul.

60 safrista é a pessoa física que presta serviço a empregador rural mediante contrato de safra, isto é, o contrato dependente de variação estacional na atividade agrária.

70 domador é a pessoa responsável pelo processo pelo qual o cavalo passa antes de aceitar ser montado pelo cavaleiro. A doma de cima é aquela que consiste em encilhar o animal e montá-lo, ensinando os comandos para direcionar o animal, realizar transições e controle da velocidade.

8 É uma profissão muito antiga, do campo. É o profissional que constrói as cercas de arame.
} 
potencial para ser explorada nas áreas rurais, uma vez que a população rural, em geral, é pouco qualificada e muitas vezes receptiva a esses baixos níveis de ganho monetário.

Por mais contraditório que pareça, esse fato pode ser visto como um ponto positivo da atividade, pois a absorção, principalmente, da mão de obra mais jovem residente no meio rural, pode, inclusive, reduzir ou retardar a saída desses jovens para a cidade, diminuindo bastante o êxodo rural. Para Carneiro (2008, p. 21), "encontram-se, sobretudo para os jovens rurais, oportunidades de postos de trabalho alternativos e/ou complementares, que colaborariam para que estes permanecessem no campo através da pluriatividade"; o autor mostra a ambiguidade do turismo rural enquanto a qualidade e a quantidade dos empregos gerados, o qual justifica a pertinência de pesquisar o impacto do turismo nas economias rurais.

Na Tabela 2, há um comparativo entre o número de empregos fixos e temporários nas propriedades investigadas. Como se pode notar em relação ao número total de vagas oferecidas, $42,1 \%$ são temporárias para os três modelos. No tocante a empregos fixos, Veiga explica a pequena ocorrência da dupla jornada de trabalho do modelo dois da seguinte forma: “[...] principalmente porque o sucesso desses negócios resulta justamente da redução de subemprego de mão de obra familiar em função do simultâneo aproveitamento de oportunidades complementares de geração de renda”. (VEIGA, 2002, p. 209).

No modelo 1, detectou-se a predominância dos empregos fixos gerados pelo setor primário, tradicionalmente esse setor conta com trabalhadores de confiança das famílias que dedicam suas vidas à propriedade. Também a ocorrência de empregos temporários, isso acontece graças ao período da safra da uva na região.

No modelo 3, observou-se um volume muito grande de vagas temporárias geradas pelo turismo, isso ocorre pela falta de vínculo empregatício, visto que os proprietários rurais ainda reclamam da sazonalidade da atividade turística. Percebeu-se nas entrevistas que esses trabalhadores são chamados nos períodos de alta temporada ou quando há necessidade de mais mão de obra. Ainda no modelo três, individuou-se que o turismo ainda gera poucos empregos fixos, mesmo que a atividade exercida na região seja, em sua absoluta maioria, o turismo rural.

Tabela 2 - Número de vagas de empregos fixos e temporários

\begin{tabular}{|c|c|c|c|}
\hline $\begin{array}{c}\text { MODELO 1 } \\
\text { Pecuária e Agricultura } \\
\text { (emp. fixo) }\end{array}$ & $\begin{array}{c}\text { MODELO 2 } \\
\text { Pecuária, Agricultura e } \\
\text { Turismo (emp. fixo) }\end{array}$ & $\begin{array}{c}\text { MODELO } 3 \\
\text { Turismo } \\
\text { (emp. fixo) }\end{array}$ & $\begin{array}{c}\text { Total de Vagas em } \\
\text { Empregos Fixos }\end{array}$ \\
\hline $59,09 \%(26)$ & $9,09 \%(4)$ & $31,81 \%(14)$ & $100 \%(44)$ \\
\hline $\begin{array}{c}\text { Pecuária e Agricultura } \\
\text { (emp. temporário) }\end{array}$ & $\begin{array}{c}\text { Pecuária, Agricultura } \\
\text { e Turismo (emp. } \\
\text { Temporário) }\end{array}$ & $\begin{array}{c}\text { Turismo } \\
\text { (emp. temporário) }\end{array}$ & $\begin{array}{c}\text { Total de Vagas em } \\
\text { Empregos Temporários }\end{array}$ \\
\hline $18,75 \%(6)$ & $9,37(3)$ & $71,87 \%(23)$ & $100 \%(32)$ \\
\hline Total Fixo + Temp. & Total Fixo+ Temp. & Total Fixo + Temp. & Empregos Fixo + Temp. \\
\hline $42,10 \%(32)$ & $9,21 \%(7)$ & $48,68 \%(37)$ & $100 \%(76)$ \\
\hline
\end{tabular}

Fonte: Pesquisa de Campo, 2014 
Na Figura 1, pode-se observar que o setor que mais emprega no Corede das Hortênsias, nas propriedades rurais ativas, em relação à atividade turística, é o setor terciário com quase $49 \%$ das vagas, somado aos trabalhadores que possuem jornada dupla e atuam tanto no setor primário quanto no terciário, chegandose a $58 \%$ dos empregos. Esse dado aponta para a especialização do turismo rural na região e corrobora a hipótese de que o turismo é uma alternativa na geração de emprego e renda nas áreas rurais dos municípios visitados.

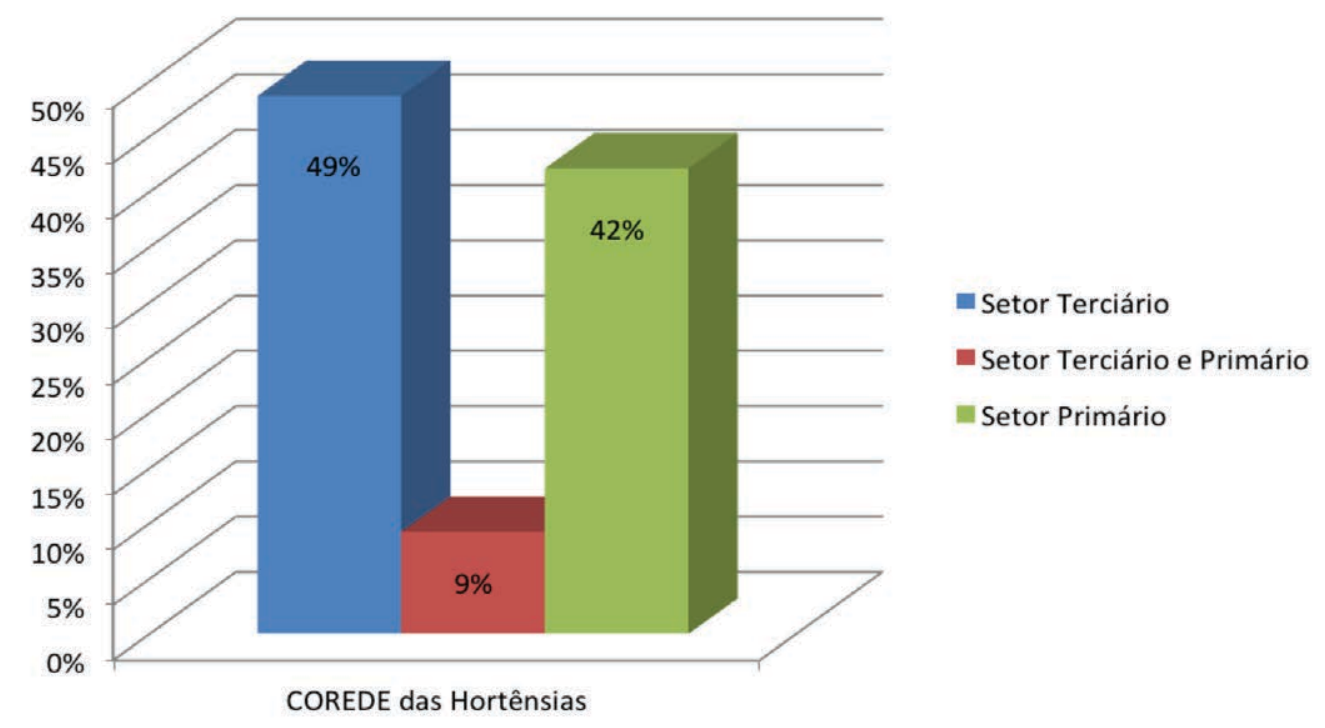

Figura 1 - Setorização dos empregos gerados

Fonte: Pesquisa de Campo, 2014

A Figura 2 ilustra a quantidade de empregos fixos e temporários gerados pelo turismo no Corede das Hortênsias. Ainda verifica-se um maior número de empregos temporários respaldado na falta de constância do rendimento gerado pela atividade; a sazonalidade do turismo foi citada por grande parte dos entrevistados como sendo o maior entrave para novas contratações.

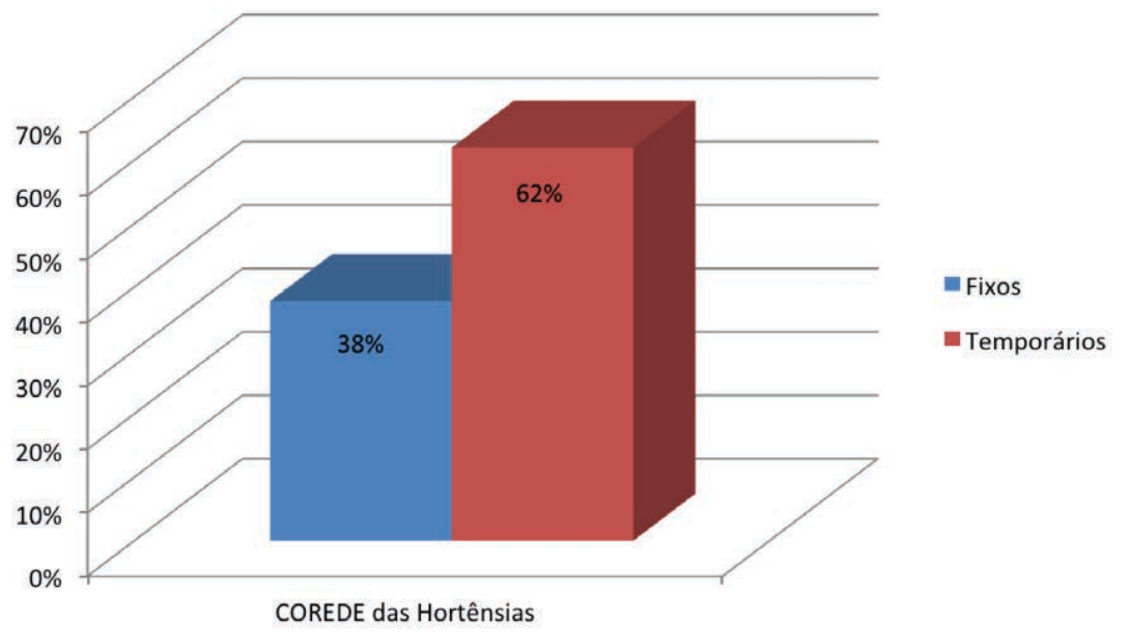

Figura 2 - Quantidade de empregos fixos e temporários

Fonte: Pesquisa de Campo, 2014 
Pode-se observar na Figura 3 a média salarial dos trabalhadores das propriedades estudadas. Foi realizado um comparativo desses valores com o Departamento Intersindical de Estudos Econômicos, Sociais e Estatísticos (DIEESE, 2015) no mês em que as entrevistas foram realizadas a fim de se estabelecer um critério de análise dos salários praticados na região. Cabe salientar que os valores são expressos em dólares por ser um indexador mais durador, para isso, a conversão foi feita a partir de dados retirados da "web page" do Banco do Brasil, cuja média anual (2014) do dólar foi de R 2,54.

No gráfico que segue, observa-se que a média salarial dos empregos fixos e temporários praticada no Corede das Hortênsias é inferior ao indicado pelo Dieese, conforme citado:

A pesquisa da Cesta Básica Nacional (Ração Essencial Mínima), realizada hoje pelo Dieese, em dezesseis capitais do Brasil, acompanha mensalmente a evolução de preços de treze produtos de alimentação, assim como o gasto mensal que um trabalhador teria para comprá-los. Outro dado importante da pesquisa são as horas de trabalho necessárias ao indivíduo que ganha salário mínimo, para adquirir estes bens. O salário mínimo necessário, também divulgado mensalmente, é calculado com base no custo mensal com alimentação obtido na pesquisa da Cesta (DIEESE, 2015).

Percebeu-se que a média salarial dos empregos temporários é mais alta do que a praticada nos empregos fixos, isso se dá porque os proprietários preferem pagar um pouco a mais nos períodos em que precisam mais dos serviços desses colaboradores do que manter o vínculo empregatício durante todo o ano e enfrentar dessa forma a sazonalidade.

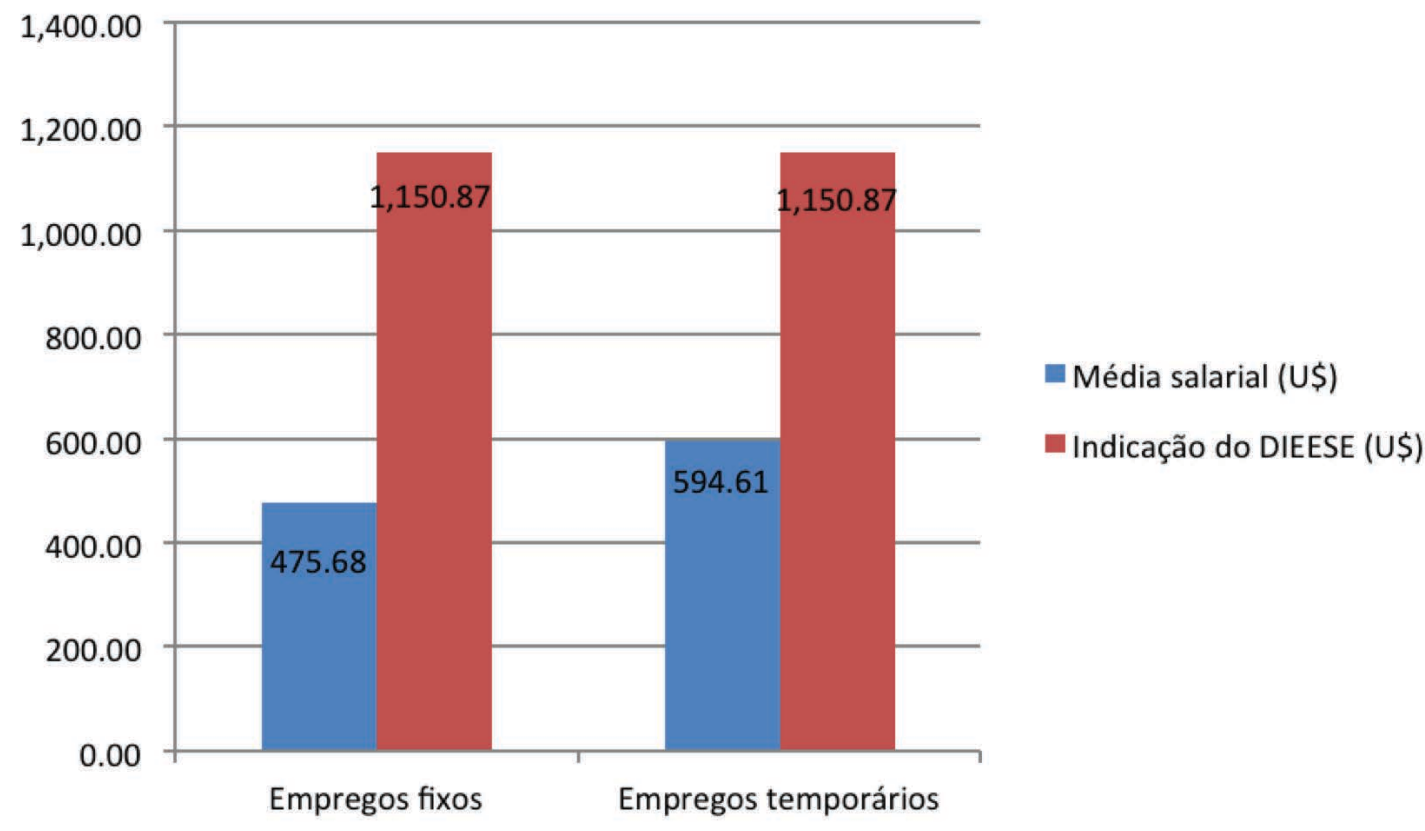

Figura 3 - Média salarial praticada no Corede das Hortênsias.

Fonte: Pesquisa de campo (2014).

De acordo com os dados obtidos, pôde-se traçar um perfil dos proprietários rurais da região e chegar a um significativo aumento da participação feminina nesse processo, lugar antes ocupado apenas por homens. Quanto ao grau de escolarização, verificou-se que os proprietários possuem formação elevada e, ao constatar que nenhum tem formação na área do turismo, é possível inferir que isso não é um fator que influencie no início da atividade na propriedade. 


\section{Considerações finais}

A fim de responder ao objetivo proposto por esta pesquisa, que era o de estabelecer o perfil da geração de empregos fixos, temporários e renda nos setores primário e terciário no Corede das Hortênsias do estado do Rio Grande do Sul, Brasil, percebeu-se que a atividade turística é geradora de empregos e renda para essas famílias e comunidade mesmo que, na maioria das vezes, com empregos temporários. Veiga (2002) confirma essa afirmação ao colocar que o setor terciário tem oportunizado geração de renda e empregos, enquanto nos setores primário e secundário, a necessidade de trabalho reduz-se. Na região estudada, o turismo gerou 37 vagas de emprego, sendo 14 fixas. As outras 23 temporárias em muitos casos são realizadas na forma de jornada dupla pelo trabalhador do primeiro setor.

De acordo com os dados analisados, detectou-se que os trabalhadores que possuem vínculo empregatício nos estabelecimentos ganham menos dos que aqueles que trabalham temporariamente. $\mathrm{E}$ isso ocorre porque os proprietários preferem driblar a sazonalidade da atividade turística contratando menos colaboradores e sempre que necessário chamando extras para cobrir as funções que são necessárias.

Enfim, este estudo revelou que o turismo no espaço rural é uma alternativa de geração de emprego e renda nas propriedades rurais do Corede das Hortênsias, de tal forma que o turismo rural é a tipologia mais encontrada, na qual a fonte essencial da família é proveniente do terceiro setor, dos serviços. A pesquisa também revelou o perfil da geração de renda tanto no primeiro como no terceiro setor e, ainda, casos em que os dois setores se juntam em uma dupla jornada de trabalho. Como esta pesquisa se deteve ao olhar dos proprietários rurais, sugere-se a realização de futuros estudos que incluam também a visão do turista em relação ao turismo rural e agroturismo praticados no Corede das Hortênsias.

A maioria dos empreendimentos estudados mostra que as atividades primárias são sua maior fonte de renda e o turismo é somente uma atividade complementar, o que permite deduzir que o ser humano continua acreditando que a produção agropastoril é mais importante que as atividades terciárias, entretanto, o turismo permite gerar alguns recursos importantes para a reprodução material e simbólica da ruralidade.

\section{Referências}

ANJOS, F. S. Agricultura familiar em transformação: os colonos-operários de Massaranduba (SC). Pelotas: UFPEL. 2003.

BERG, S. Snowball sampling - I. In: Enciclopedia of Statistical Sciences. New York: Willey, 2006. p. 528-532.

BLANCO, E. S. O turismo rural em áreas de agricultura familiar: as "novas ruralidades" e a sustentabilidade do desenvolvimento local. Caderno Virtual de Turismo. Rio de Janeiro, v. 4, n. 3, p. 44-49, 2004 .

BOAVEnTURA, E. Metodologia da Pesquisa: monografia, dissertação, tese. São Paulo: Atlas, 2004.

BRASIL. Ministério do Turismo. Plano Nacional do Turismo: diretrizes, metas e programas. 2003 2007. Brasília: Ministério do Turismo, 2003. 
CARNEIRO, M. J. De terra de plantação à terra de lazer. In: Ruralidades Contemporâneas, modos de viver e pensar o rural na sociedade brasileira. Rio de Janeiro: Maual X, 2008, p. 23-50.

COREDES. Pró-RS IV. Propostas estratégicas para o desenvolvimento regional do estado do Rio Grande do Sul. Passo Fundo: Passografic, 2010.

. Fórum dos Coredes do Rio Grande do Sul. In: XIII ENCONTRO ANUAL DE AVALIAÇÃO E PLANEJAMENTO DOS COREDES. CARTA DE SÃO BORJA. Anais... Porto Alegre: Governo do Rio Grande do Sul, 2010b.

CORREA, L. A segunda residência como indutora da urbanização em áreas litorâneas na contemporaneidade. GEO UERJ. Rio de Janeiro, n. 28, p. 291-307, 2016.

CROSBY, A.; MOREDA, A. Desarollo y gestión del turismo em áreas rurales y naturales. Madrid: Centro Europeo de Formación Ambiental y Turística, 1996.

DEL GROSSI, M.; SILVA, J. G. 0 novo rural: uma abordagem ilustrada. Londrina: IAPAR, 2002.

DEPARTAMENTO INTERSINDICAL DE ESTATÍSTICA E ESTUDOS SOCIOECONÔMICOS. Cesta Básica Nacional. Disponível em: 〈http://www.dieese.org.br/analisecestabasica/salarioMinimo.html〉. Acesso em: 22 abr. 2015.

FOOD AND AGRICULTURE ORGANIZATION. Perspectivas de la agricultura y del desarrollo rural en las Américas: una mirada hacia América Latina y el Caribe 2014. Costa Rica: Cepal, FAO, IICA, 2014.

FROELICH, J. M.; RODRIGUES, I. Atividade turística e espaço agrário: considerações exploratórias sobre o município de Restinga Seca (RS). In: ALMEIDA, J. A. de J.; FROELICH, J. M.; RIEDL, M. (Org.). Turismo rural e desenvolvimento sustentável. Campinas, SP: Papirus, 2000, p. 85-110.

FULLER, A. M. Part-time farming and the farm family: a note for future research. Sociologia Ruralis. London, v. 23, n. 1, p. 5-9, 1983.

FUNDAÇÃO DE ECONOMIA E ESTATÍSTICA. Dados 2011. Disponível em: 〈http://www.fee.rs.gov.br/〉. Acesso em: 09 abr. 2014.

GEERTZ, C. La interpretación de las culturas. Barcelona: Gedisa, 2003.

GIBBS, G. Análise de dados qualitativos. Porto Alegre: Artmed, 2009.

MANOSSO, F. C.; SALOMÉ, M. V.; CARVALHO, A. T. de. Turismo rural na região norte do estado do Paraná: conceito e prática. Caderno Virtual de Turismo. Rio de Janeiro, v. 1, n. 10, p. 24-35, 2010.

MATTEI, L. A relevância da família rural como unidade de análise nos estudos sobre pluriatividade e desenvolvimento rural. In: XLIII ENCONTRO DA SOCIEDADE BRASILEIRA DE ECONOMIA E SOCIOLOGIA RURAL. Anais... Ribeirão Preto: Sober, 2005, p. 137-165.

PELLIN, V. A atividade turística no espaço rural catarinense. Caderno Virtual de Turismo. Rio de Janeiro, v. 2, n. 4, p. 1-8, 2004.

RODRIGUES, A. B. Turismo Eco-Rural: interfaces entre o ecoturismo e o turismo rural. In: ALMEIDA, J. A. de J.; FROELICH, J. M.; RIEDL, M. (Org.). Turismo rural e desenvolvimento sustentável. Campinas, SP: Papirus, 2000, p.111-126.

ROQUE, A.; MENDONÇA, M. C. Bases para a produção do turismo no espaço rural. In: CONGRESSO BRASILEIRO DE TURISMO RURAL - 1999. Anais... Piracicaba: Fealq, 1999. 
RUBIO, P. Modelización de los cambios y evolución reciente del sistema rural español. Boletín de la Asociación de Geógrafos Españoles (AGE). España, n. 54, p. 203-235, 2010.

SANTOS, E. de O. et al. El papel de Turismo em el Espacio Rural de São José dos Ausentes, Brasil. El Periplo Sustentable, v. 27, p. 21-53, 2014.

SANTOS, E.; VIANNA, S.; GULLO, M. C. R. Evolución de la renta, empleo y sueldos en propiedades rurales que ofrecen Agroturismo y Turismo rural en la Mitad Sur de Rio Grande do Sul, Brasil (19972011). El periplo sustentable. Toluca, n. 23, p. 27-47, 2012.

SCHNEIDER, S. A pluriatividade na agricultura familiar. Porto Alegre: UFRGS, 2003 a.

. Teoria social, agricultura familiar e pluriatividade. Rev. Bras. Ci. Soc. São Paulo, v. 18, n. 51, p. 99-122, 2003b.

SCHNEIDER, S.; FIALHO, M. A. V. Atividades não agrícolas e turismo rural no Rio Grande do Sul. In: ALMEIDA, J. A. de J.; RIEDL, M. Turismo Rural: ecologia, lazer e desenvolvimento. Bauru: Edusc, 2000, p. 14-50.

SILVA, J. G.; VILARINHO, C.; DALE, P. Turismo em áreas rurais: suas possibilidades e limitações no Brasil. In: ALMEIDA, J. A. de J.; FROELICH, J. M.; RIEDL, M. (Org.). Turismo rural e desenvolvimento sustentável. Campinas, SP: Papirus, 2000, p. 15-62.

SILVA, N.; FRANCISCO, A. C. de. THOMAZ, M. S. Turismo rural como fonte de renda das propriedades rurais: um estudo de caso numa pousada rural na região dos Campos Gerais no estado do Paraná. Caderno Virtual de Turismo. Rio de Janeiro, v. 2, n. 10, p. 22-37, 2010.

SILVERMAN, D. Interpretação de dados qualitativos. Porto Alegre: Artmed, 2009.

THOMÉ, H. Turismo rural y campesinado, una aproximación social desde la ecologia la economia y la cultura. Convergencia. Toluca, v. 47, n. 15, p. 237-261, 2008.

Turismo en áreas rurales, hacia un enfoque de espacios compatibles entre el campo y la ciudad. Artículos y Ensayos de Sociología Rural. Texcoco, n. 9, p. 65-78, 2010.

TOLEDO, V. M. Estudiar lo rural desde una perspectiva intersdisciplinaria: el enfoque ecológicosociológico. In: Globalización, crisis y desarrollo rural en América Latina: memoria de sesiones plenarias. México: Universidad Autónoma Chapingo, Colegio de Postgraduados,1998. 172p.

VEIGA, J. E. Cidades Imaginárias: o Brasil é menos urbano do que se calcula. Campinas: Autores Associados, 2002

ZIMMERMMAN, A. Planejamento e organização do turismo rural no Brasil. In: ALMEIDA, J. A. de J.; FROELICH, J. M.; RIEDL, M. (Org.). Turismo rural e desenvolvimento sustentável. Campinas, SP: Papirus, 2000, p. 127-142. 